\section{D) Check for updates}

Cite this: Mater. Adv., 2021, 2,6380

Received 25th June 2021,

Accepted 21st August 2021

DOI: $10.1039 / \mathrm{d} 1 \mathrm{ma00556a}$

rsc.li/materials-advances

\title{
Energetic carbon precursors for micro-supercapacitor printing $\dagger$
}

\author{
Christin Gellrich, Stefanie Lochmann, Thomas Otto, Julia Grothe and \\ Stefan Kaskel (iD *
}

\begin{abstract}
A highly energetic carbon precursor suitable for soft lithographic processing based on acetylene dicarboxylic acid is presented. High-resolution micro-supercapacitors with line width down to $500 \mathrm{~nm}$ are produced using solvent assisted nanoimprint lithography. The resulting nonporous carbons exhibit remarkably low specific resistance down to $6.9 \times 10^{-5} \Omega \mathrm{m}$ pyrolyzed at $800{ }^{\circ} \mathrm{C}$. The interdigital electrodes show excellent device capacitances of up to $1.32 \mathrm{mF} \mathrm{cm}{ }^{-2}$ with an average capacitance retention of $97 \%$ after 10000 cycles. Tailoring the performance is achieved by variation of electrode distances and carbonization temperatures.
\end{abstract}

\section{Introduction}

The establishment of portable electronic devices in medicine, technical applications and consumer electronics also attracted an immense attention in research of miniaturized modules. Pursuing this objective, recent efforts in nanotechnology and the development of maintenance-free microelectronics such as autonomous micro-sensors or medical implants and nanorobotics also stimulated the development of micro-scale energy

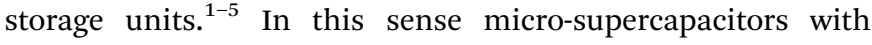
remarkable power densities, fast charge/discharge rates and ultra-long cycle life assembled on ultra-small device areas are extensively studied. ${ }^{6,7}$ A wide range of different surface structuring and electrode deposition techniques are established and approaches concerning simple, lightweight packaging and leakage safety are investigated. ${ }^{8-10}$ Prominent methods for producing interdigital electrodes are for example direct laser writing, ${ }^{11,12}$ inkjet printing ${ }^{10,13,14}$ or stamping and screen printing. ${ }^{15-17}$ Recently used inks include carbon materials like graphene and graphene oxide, ${ }^{10,18,19} \mathrm{CNTs}^{20}$ as well as MXenes. ${ }^{14,17,21}$

Nanoimprint lithography (NIL) is a promising technique for the production of high-resolution interdigital carbon electrodes. $^{22,23}$ The approach is using liquid carbon precursors and enables binder free direct printing of precursor structures. After pyrolysis the porous carbon electrodes adhere to the substrate. Compared to, for example, photolithographic techniques, the nanoimprint lithography facilitates fast and lowcost printing and high process throughput. A typical limiting

TU Dresden, Institute of Inorganic Chemistry, Bergstraße 66, 01069 Dresden, Germany.E-mail: Stefan.kaskel@tu-dresden.de

$\dagger$ Electronic supplementary information (ESI) available. See DOI: 10.1039/d1ma00556a resolution achieved via soft lithographic techniques using PDMS as stamping material is around $200 \mathrm{~nm} .^{24,25}$

The ongoing trend towards ever smaller mobile devices forces the development of flexible, stretchable and transparent devices. $^{26}$ Especially in the production of e-skin, wearable devices or biomedical applications a high degree of shape stability and elasticity is required. ${ }^{13,27,28}$ In this sense polymer or silicon substrates are used to produce microsupercapacitors. ${ }^{29}$ However, printing carbon precursors onto flexible substrates requires carbonization temperatures significantly above the melting point of the substrate. ${ }^{29}$ Hence, for porous carbon printing applications precursors transforming into conductive carbons at low temperatures are required.

Typical flexible substrates consist of polyimide (Kapton), PET or PDMS. ${ }^{8,30-32}$ The carbon properties like electronic conductivity and porosity are highly dependent on the carbonization temperature. ${ }^{33}$ Provided that the electronic conductivity has a decisive influence on the performance of highresolution micro-supercapacitors, the formation of a suitable carbon material with high electronic conductivity and appropriate surface area remains to be a challenge. Graphene and other particle dispersions afford high surface areas when deposited on substrates but continuous processing via printing technologies is hampered by clogging of nozzles and stamps.

Micro-structuring provides a good accessibility and an increased carbon surface area can even be achieved without porous carbons. A challenge is to envision molecular precursors graphitizable at low temperature $\left(<900{ }^{\circ} \mathrm{C}\right)$. In this regard, energetic carbon precursors based on alkynes are promising candidates. Acetylene is a widely used gaseous precursor for CNT production and CVD processes. It is a carbon rich molecule, promising for the formation of graphitic carbon structures. $^{34-36}$ For the processing of a liquid carbon precursor 


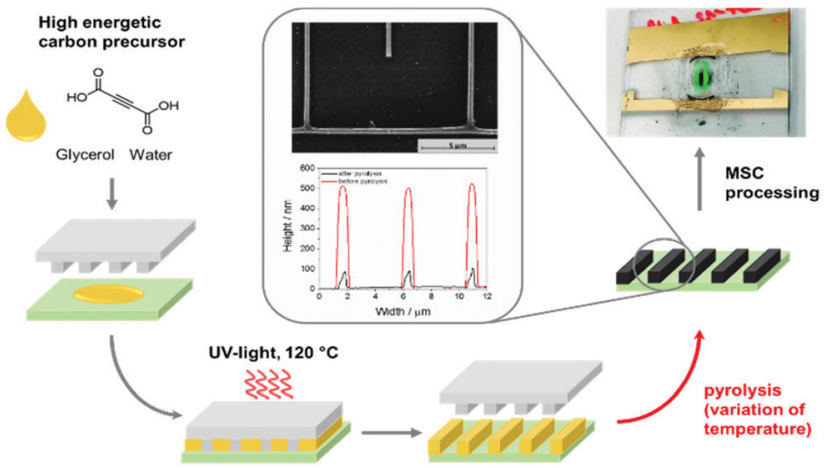

Fig. 1 Schematic procedure of the SA-NIL process using a high energetic carbon precursor and further MSC processing.

additional functional groups like carboxylate groups are ideal as the $\mathrm{CO}_{2}$ elimination is favorable. In this sense we envisioned acetylene dicarboxylic acid to be an ideal precursor for microcontact printing. In the following we present an acetylene dicarboxylic acid-based carbon precursor for the nanoimprint processing of micro-supercapacitor with a high resolution inplane interdigital structure (Fig. 1).

\section{Results and discussion}

A new energetic carbon precursor system is developed to produce in-plane micro-supercapacitors (MSC) with interdigital geometry using the solvent assisted nanoimprint lithography (SA-NIL) technique (Fig. 1).

A suitable precursor must fulfill various requirements regarding processability and shape stability. The selected solvent system should have a high vapor pressure to ensure a fast curing under thermal or UV-treatment, forming the desired homogeneous and stable pattern. The main focus is to reduce the necessary carbonization temperature significantly below $900{ }^{\circ} \mathrm{C}$ and guarantee a high electrical conductivity at the same time.
We study a promising energy-rich carbon precursor based on acetylene dicarboxylic acid $\left(\mathrm{H}_{2} \mathrm{ADC}\right)$, glycerol and sulfuric acid. During pattering of the mixture, the structure is cured through polymerization triggered by heating and UV-radiation. Three different interdigital structures are tested and compared using the same line height of $500 \mathrm{~nm}$ but different line width of $10 \mu \mathrm{m}$ (IDE 500/10), $5 \mu \mathrm{m}$ (IDE 500/5) and $1 \mu \mathrm{m}$ (IDE 500/1). The influence of the carbonization temperature on the material and structural characteristics like conductivity, porosity and line heights as well as the electrochemical performance are explored.

\section{Precursor characterization}

The processability of the dissolved acetylene dicarboxylic acid is increased using glycerol as esterification agent in order to obtain a more homogeneous precursor. At the same time, the polymerization of these educts is promising to form stable structures during NIL-printing.

In our work, the triol glycerol serves as an optimal polymerization agent. To characterize and optimize the polymerization and esterification degree, various heat and UV-radiation treatments are analyzed by infrared spectroscopy (Fig. 2a). The treated and untreated acid-alcohol mixtures exhibit very similar IR-spectra showing mainly the characteristic stretches of the pure dicarboxylic acid and glycerol. These are namely the valence and deformation vibration of the OH-groups $\left(\sim 3400 \mathrm{~cm}^{-1}\right)$ and the characteristic vibration of the carboxyl-group at $1650 \mathrm{~cm}^{-1}$ caused by the acid, glycerol and $20 \mathrm{wt} \%$ of water.

To enhance the polymerization, concentrated sulfuric acid is added to the solution, treated again with UV-light and cured at $100{ }^{\circ} \mathrm{C}$ afterwards. In the polymerized system the two characteristic bands of the ester groups are clearly visible $\left(\nu_{\text {as }}(\mathrm{C}-\mathrm{C}(=\mathrm{O})-\mathrm{O})\right.$ at $1250 \mathrm{~cm}^{-1}$ and $\nu_{\text {as }}(\mathrm{O}-\mathrm{C}-\mathrm{C})$ at $\left.1080 \mathrm{~cm}^{-1}\right)$. Furthermore, due to the formation of the ester, the symmetric valence stretch of the $\mathrm{C} \equiv \mathrm{C}$ triple bond at $2300 \mathrm{~cm}^{-1}$ clearly emerges, because the symmetry of $\mathrm{H}_{2} \mathrm{ADC}$ is reduced and the stretch of the $\mathrm{C} \equiv \mathrm{C}$ triple bond becomes IR-active. A slight (a)

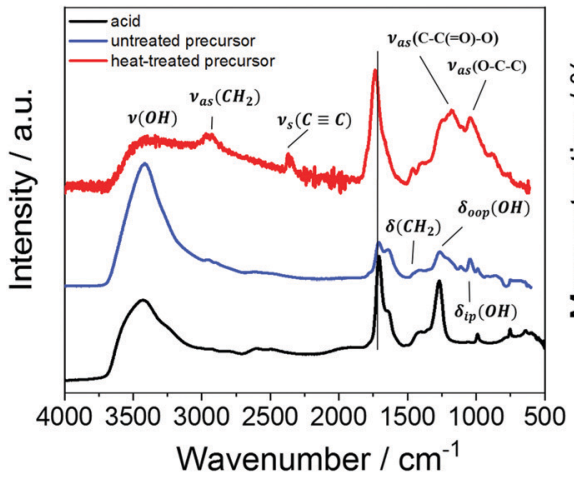

(b)

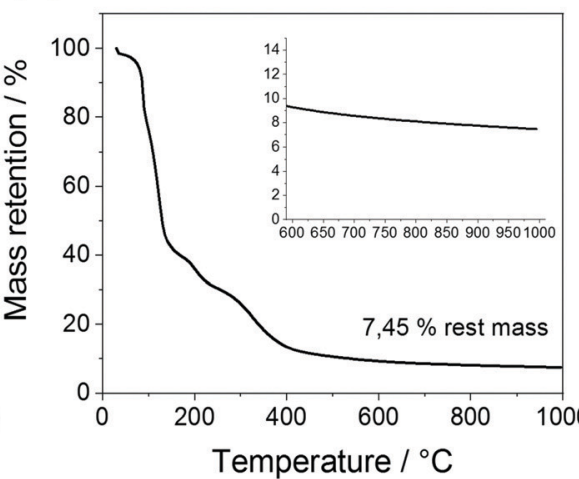

(c)

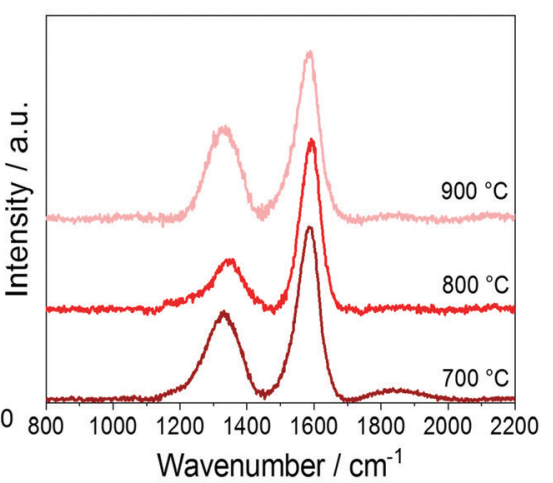

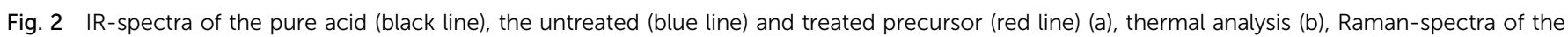
precursor powders carbonized at $700{ }^{\circ} \mathrm{C}, 800{ }^{\circ} \mathrm{C}$ and $900{ }^{\circ} \mathrm{C}$ in Ar-atmosphere (c). 
shift in the stretch of the carboxylic group to higher wavenumbers can be recognized and is now observed at $1710 \mathrm{~cm}^{-1}$, the typical range for the $\mathrm{C}=\mathrm{O}$ vibration in the alpha-beta unsaturated ester group (usually at 1750-1715 $\mathrm{cm}^{-1}$ ). ${ }^{37,38}$

The TG measurements suggest that a temperature of $450{ }^{\circ} \mathrm{C}$ is sufficient to completely transform the organic precursor, because at higher temperatures only a small mass loss is observed (Fig. 2b).

To characterize the surface properties of the material, nitrogen physisorption and Raman measurements are performed using the carbon powder carbonized at varying temperature. Therefore, carbon powders are prepared at carbonization temperatures between 500 to $900{ }^{\circ} \mathrm{C}$. The powders show no appreciable specific surface area at all analyzed pyrolysis temperatures, indicating a total absence of porosity. In the Raman spectra, the presence of highly graphitic carbon, carbonized at temperatures between 700 to $900{ }^{\circ} \mathrm{C}$ under Argon, can be observed. Due to the high reactivity, even conversion temperatures as low as $300{ }^{\circ} \mathrm{C}$ in air are sufficient to produce this allotrope of carbon (ESI, $\dagger$ Fig. S1). This observation is in agreement with observations by Bourlinos et al., who investigated the formation of a carbonaceous solid after pyrolysis of monopotassium salt of acetylene dicarboxylic acid at $300{ }^{\circ} \mathrm{C}$. Besides the characteristic D-band at $1350 \mathrm{~cm}^{-1}$ for disordered carbon structures, the G-band at $1595 \mathrm{~cm}^{-1}$ assigned to the graphitic carbon is present, ${ }^{37}$ rendering the precursor as promising for the transformation into materials for electrochemical energy storage (Fig. 2c). The powder carbonized at $800{ }^{\circ} \mathrm{C}$ showed the lowest ratio of $I_{\mathrm{D}} / I_{\mathrm{G}}$ with 0.28 and therefore the highest amount of graphitic carbon, followed by $700{ }^{\circ} \mathrm{C}(0.50)$ and $900{ }^{\circ} \mathrm{C}(0.54)$. The drop of the $I_{\mathrm{D}} / I_{\mathrm{G}}$ ratio at $900{ }^{\circ} \mathrm{C}$ is probably caused by the increasing degradation of the carbon material at high temperatures.

The electrochemical properties of the carbon material are investigated using compact thin films after different carbonization temperatures between 600 and $900{ }^{\circ} \mathrm{C}$ (Table 1). As expected, the electrical conductivity increases with increasing temperatures due to a higher graphitization. ${ }^{39}$ The lowest resistance is achieved for the sample carbonized at $800{ }^{\circ} \mathrm{C}$ with $6.92 \times 10^{-5} \Omega \mathrm{m}$ due to the highest amount of graphitic carbon at this temperature. The specific resistance for the sample prepared at $900{ }^{\circ} \mathrm{C}$ is slightly higher probably due to the increasing carbon degradation and possible cracking occurring especially at high temperatures. A dramatic increase in the resistance emerges at temperatures below $700{ }^{\circ} \mathrm{C}$.

Table 1 Specific four-point resistances of carbon thin films after different pyrolysis temperatures under $\mathrm{Ar}$

\begin{tabular}{llll}
\hline $\begin{array}{l}\text { Temperature } \\
{\left[{ }^{\circ} \mathrm{C}\right]}\end{array}$ & $\begin{array}{l}\text { Resistance } \\
{[\mathrm{k} \Omega]}\end{array}$ & $\begin{array}{l}\text { Film thickness } \\
{[\mathrm{nm}]}\end{array}$ & $\begin{array}{l}\text { Specific resistance } \\
{[\Omega \mathrm{m}]}\end{array}$ \\
\hline 600 & $87.5 \times 10^{3}$ & 820 & 71.75 \\
700 & 6.850 & 640 & $4.384 \times 10^{-3}$ \\
800 & 0.407 & 170 & $6.919 \times 10^{-5}$ \\
900 & 0.330 & 450 & $1.485 \times 10^{-4}$
\end{tabular}

After processing at $600{ }^{\circ} \mathrm{C}$ the material showed unacceptably low conductivity. The loss of conductivity could be caused by the minimal increase of organic residues in the material, which probably have a high impact on the overall resistance. However, the compact thin films pyrolyzed at $800{ }^{\circ} \mathrm{C}$ and $700{ }^{\circ} \mathrm{C}$ showed remarkably low specific resistances which are about three times lower than for comparable carbon precursors at those temperatures. ${ }^{40}$ Therefore, we focused especially on pyrolysis temperatures between 700 and $900{ }^{\circ} \mathrm{C}$ for the subsequent preparation of micro-supercapacitors.

\section{Nanoimprint lithography}

Due to the promising results of the powder characterization, the precursor was applied in the nanoimprint process. In general, the generation of homogeneous crack-free and completely separated electrode fingers is a crucial requirement to obtain high performance interdigital electrodes. The nanoimprint lithography is a suitable procedure to generate highresolution structures. The short distances between the electrodes, created with this technique, are an important factor to accelerate the ion transport and reduce the diffusion resistance. In this work, we present the printing of high-resolution interdigital micro-structures with line widths of $500 \mathrm{~nm}$ and distances down to only $1 \mu \mathrm{m}$ using the investigated energy-rich carbon precursor. The characteristic structure parameters are summarized in Table 2.

The precursor is an ideal candidate for application of the SANIL process, because, using water as solvent, it provides an ideal viscosity and curability at moderate temperatures and UVradiation.

After the printing process at $120{ }^{\circ} \mathrm{C}$, lines with heights of around $500 \mathrm{~nm}$ are produced (Fig. 3). The etching depth of the stamp is $500 \mathrm{~nm}$. Typically, the line height is lower than this value because the solvent is evaporated during printing. In this case, it indicates significant swelling of the printed lines at high humidity. Only for the IDE 500/10 the line height is lower with $380 \mathrm{~nm}$. In the subsequent SEM image precursor droplets along the patterned lines are visible, which might promote emergence of short circuits in the final MSCs. The formation of droplets together with the swelling of the lines is caused by the hydrophilic nature of the precursor and is especially occurring when the structures are stored at room temperature. To prevent these side effects and the appearance of short circuits of electrodes, the structures should be stored at $120{ }^{\circ} \mathrm{C}$ before carbonization.

After pyrolysis at $900{ }^{\circ} \mathrm{C}$, almost no residues between the lines are visible, but a homogenous pattern with clearly separated and completely contacted electrode fingers is observed.

Table 2 Geometrical parameters of the used interdigital structures

\begin{tabular}{llll}
\hline Structure & Line width $[\mathrm{nm}]$ & Distance $[\mu \mathrm{m}]$ & Finger length $[\mu \mathrm{m}]$ \\
\hline IDE 500/10 & 500 & 1 & 400 \\
IDE 500/5 & 500 & 5 & 400 \\
IDE 500/1 & 500 & 10 & 400
\end{tabular}




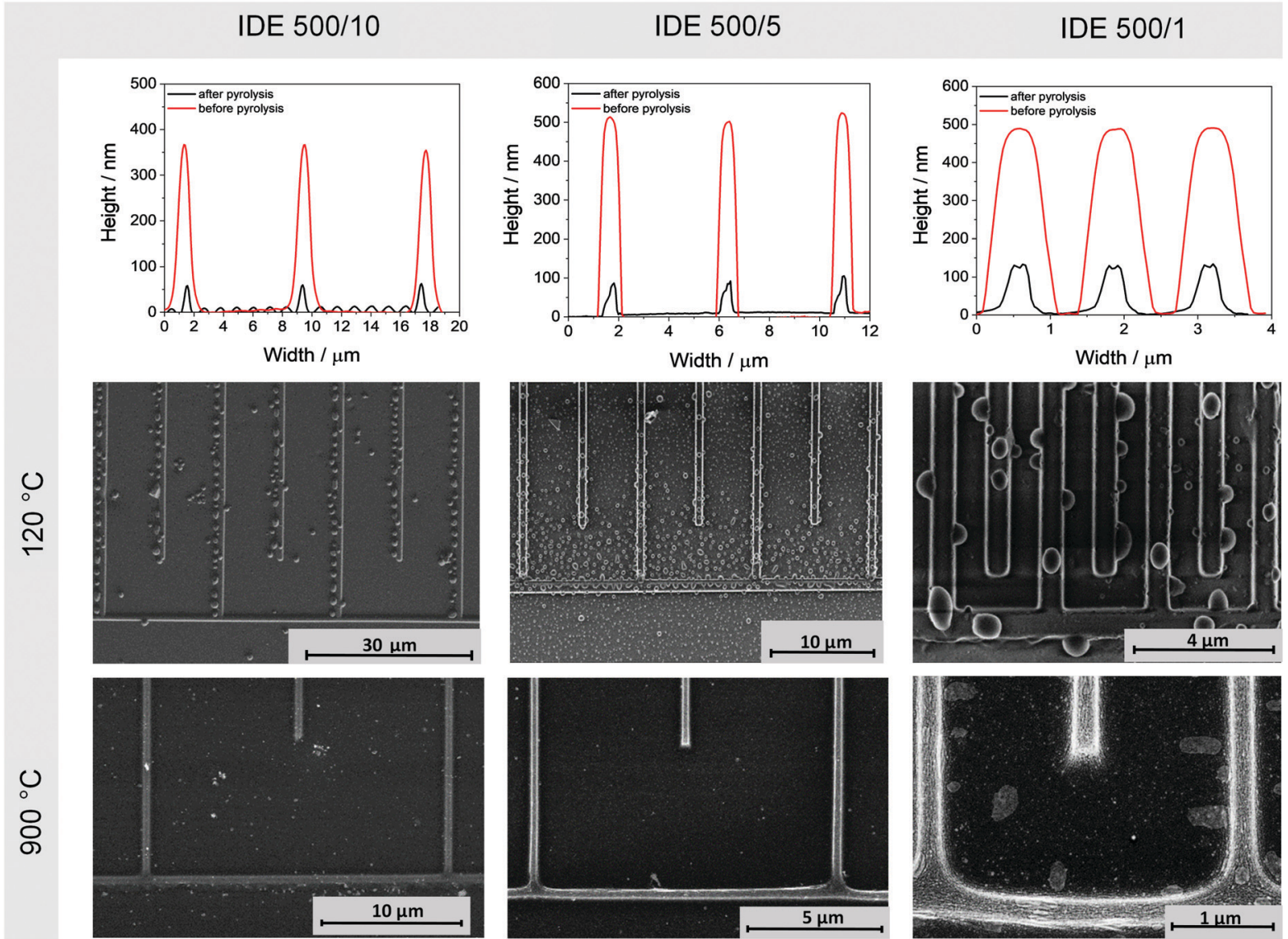

Fig. 3 Height profiles (after printing red lines (polymer), after pyrolysis black lines (carbon)) of the different structures and SEM images of the three different structures after printing at $120{ }^{\circ} \mathrm{C}$ and after carbonization at $900{ }^{\circ} \mathrm{C}$.

During the pyrolysis high volume shrinkage and height loss of the lines down to $60-140 \mathrm{~nm}$ occurs. The average line height, which was achieved for all structures and all temperatures, allows an electrochemical application. Interestingly, a layered structural characteristic of the resulting carbon material can be observed in the SEM image (Fig. 3) for the pyrolyzed IDE 500/1 structure indicating the formation of graphitic domains.
In analogy to the structures pyrolyzed at $900{ }^{\circ} \mathrm{C}$, carbonization temperatures of $800{ }^{\circ} \mathrm{C}$ and $700{ }^{\circ} \mathrm{C}$ are analyzed. Theoretically, an increase in the achieved line heights due to the decrease of graphitization is expected. However, no remarkable line height and width differences could be observed probably because the graphitization state is still very high at these temperature ranges (ESI, $\uparrow$ Fig. S2), making the precursor an interesting material for further electrochemical applications. (a)

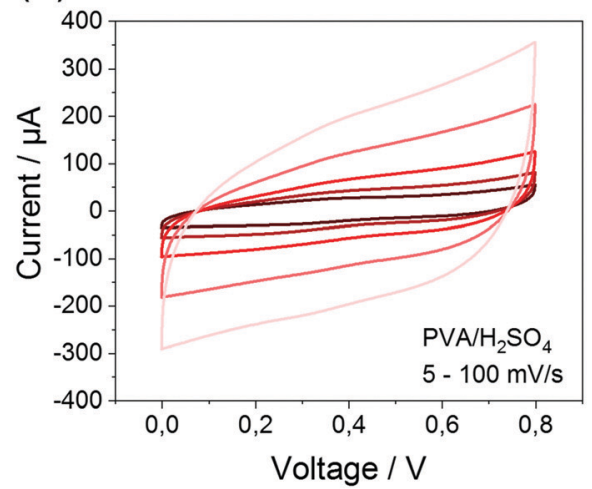

(b)

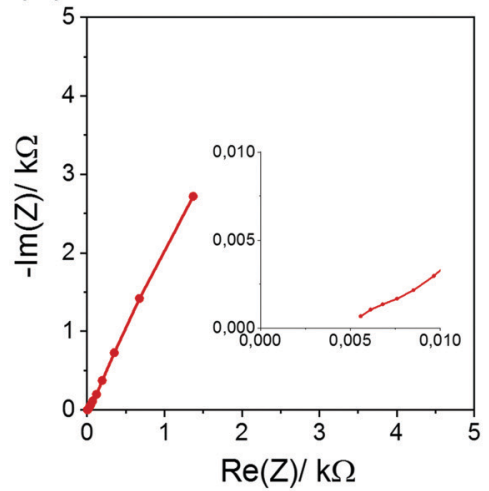

(c)

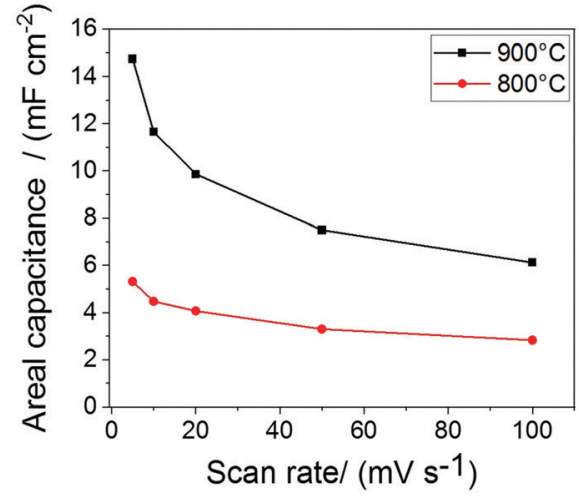

Fig. 4 Electrochemical characterization of the thin film EDLC (CV-curves) (a), GCD-curves (b), Nyquist plot (c). 


\section{Electrochemical characterization}

To analyze the basic electrochemical behavior of the carbon bulk material compact thin films and sandwich type EDLCs are prepared and investigated (Fig. 4). For the precursor pyrolyzed at $900{ }^{\circ} \mathrm{C}$, a high specific areal capacitance of $14.8 \mathrm{mF} \mathrm{cm}^{-2}$ is reached. The system shows a low internal series resistance of $5 \Omega$, which underlines the high conductivity of the carbon. Compared to that, the carbon material pyrolyzed at $800{ }^{\circ} \mathrm{C}$ reaches an areal capacitance of $5.3 \mathrm{mF} \mathrm{cm}^{-2}$.

The interdigital MSCs are electrochemically characterized using a PVA/ $\mathrm{H}_{2} \mathrm{SO}_{4}$-electrolyte. In Fig. 5, these results are shown for the IDE 500/10 exemplarily as well as for the IDE 500/5 and IDE 500/1 (ESI, $\dagger$ Fig. S4) all pyrolyzed at $900{ }^{\circ} \mathrm{C}$.

The CV-curves of all analyzed structures show a characteristic rectangular shape even at high scan rates. The Nyquist plot exhibits the typical form, which is expected for capacitive systems. The ESR (equivalent series resistance) ranges between 4-6 $\mathrm{k} \Omega$ and is much higher compared to the thin film EDLCs caused by the small line width of the interdigital structure. Theoretically, it is expected that the capacitance increases with smaller electrode distances, because of smaller diffusion pathways. This trend can also be seen for the analyzed geometries. Here, the IDE 500/1 shows with $1.32 \mathrm{mF} \mathrm{cm}^{-2}$ the highest device capacitance in comparison to the device capacitance of IDE $500 / 5$ with $0.40 \mathrm{mF} \mathrm{cm}^{-2}$ and IDE $500 / 10$ with $0.1 \mathrm{mF} \mathrm{cm}^{-2}$. Due to the lowest distance, IDE 500/1 shows the lowest diffusion resistance and therefor exhibits the lowest ESR with only
Table 3 Device capacitances of all structures after pyrolysis at varying temperatures under argon

\begin{tabular}{llll}
\hline $\begin{array}{l}\text { Temperature } \\
{\left[{ }^{\circ} \mathrm{C}\right]}\end{array}$ & $\begin{array}{l}\text { IDE 500/10 } \\
{\left[\mathrm{mF} \mathrm{cm}^{-2}\right]}\end{array}$ & $\begin{array}{l}\text { IDE 500/5 } \\
{\left[\mathrm{mF} \mathrm{cm}^{-2}\right]}\end{array}$ & $\begin{array}{l}\text { IDE 500/1 } \\
{\left[\mathrm{mF} \mathrm{cm}^{-2}\right]}\end{array}$ \\
\hline 900 & 0.10 & 0.40 & 1.32 \\
800 & 0.16 & 0.04 & 0.48 \\
700 & 0.18 & 0.02 & 0.22
\end{tabular}

$4 \mathrm{k} \Omega$. Surprisingly, very high device capacitances for all structures could be reached, despite the porosity and specific surface area of the carbon material is moderate. This underlines the importance of the implementation of a highly conductive material as electrode material to achieve high capacitances, which greatly compensates a possible absence of a high surface area carbon. Moreover, the high-resolution pattern increases the outer surface area and the accessibility of the electrodes. Furthermore, the influence of the carbonization temperature on the electrochemical performance are investigated. The calculated device capacitances for all structures at different carbonization temperatures are shown in Table 3.

Because the IDE 500/1 exhibits the highest capacitance, the CV-curves, Nyquist plots and rate capability of the three analyzed temperatures are shown in detail in Fig. 6a-c. As expected, the capacitances decrease with lower carbonization temperatures, because the graphitization and therefore conductivity decreases. Because of the absence of porosity an effect on the capacitance with temperature change can be neglected. (a)

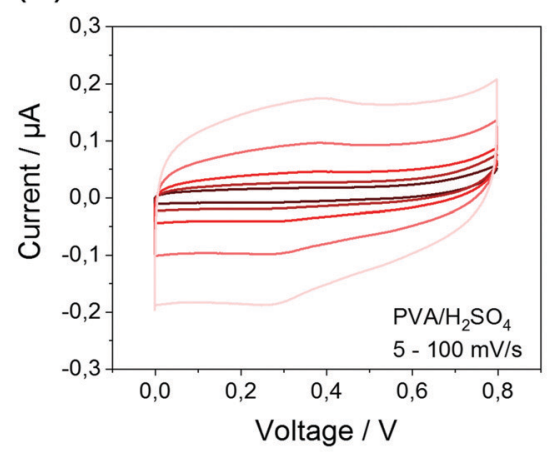

(d)

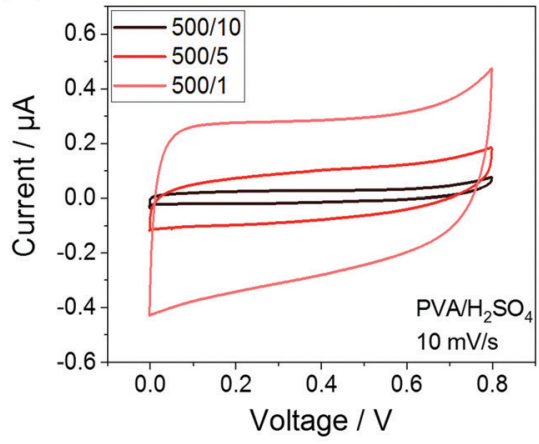

(b)

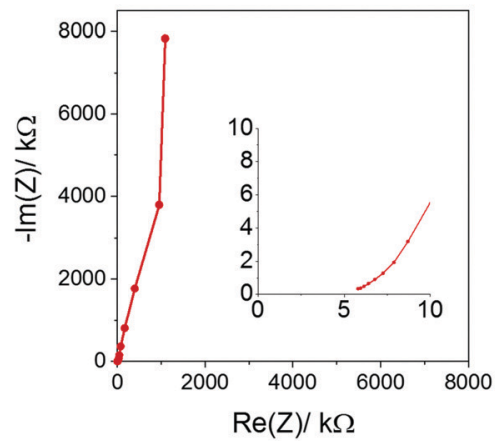

(e)

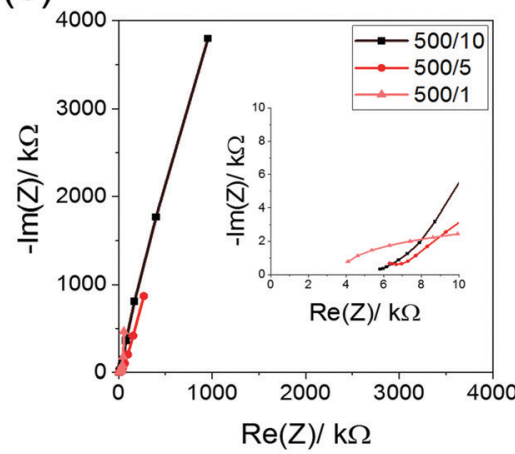

(c)

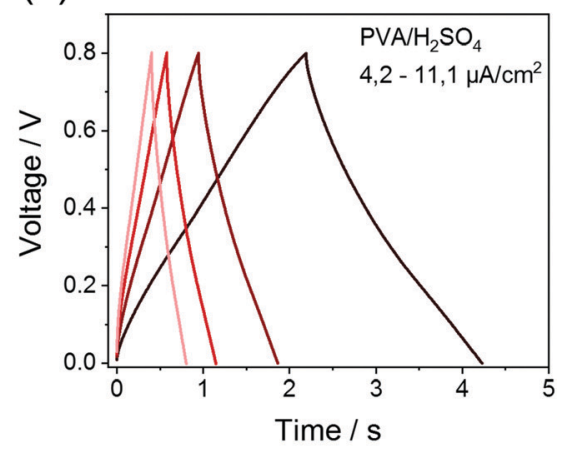

(f)

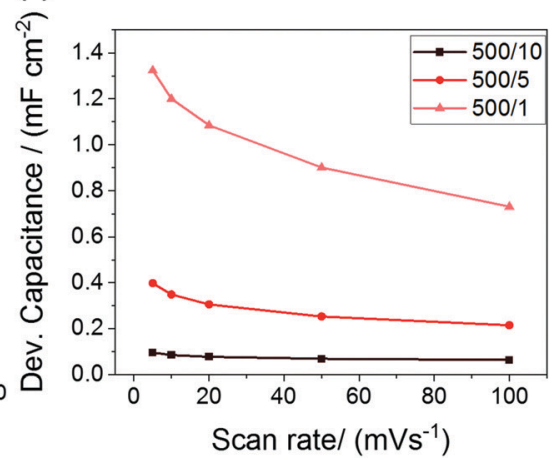

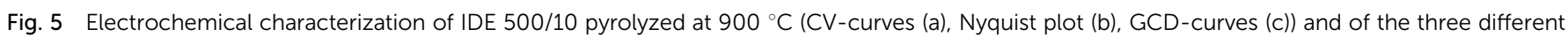
structures (CV-curves (d), Nyquist plot (e), device Capacitances (f)). 
(a)

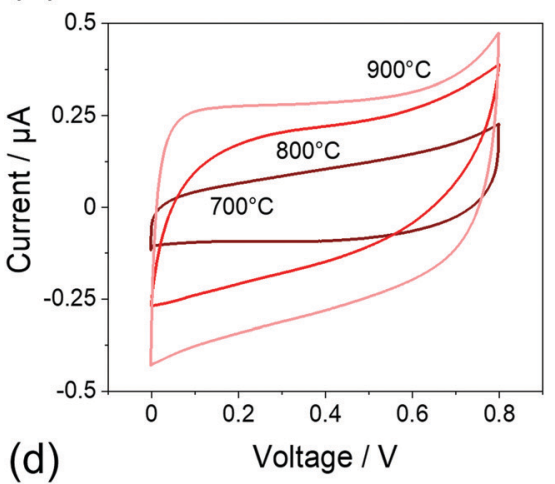

(d)

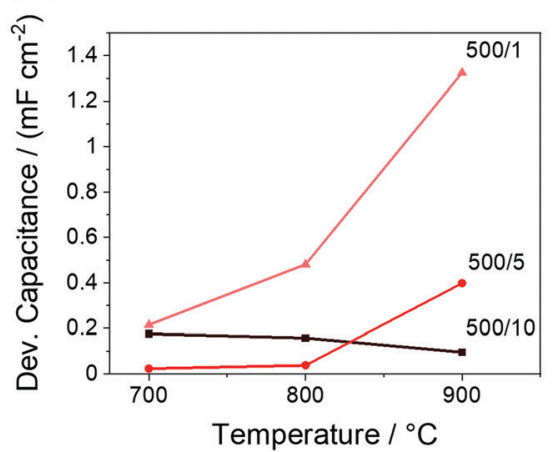

(b)
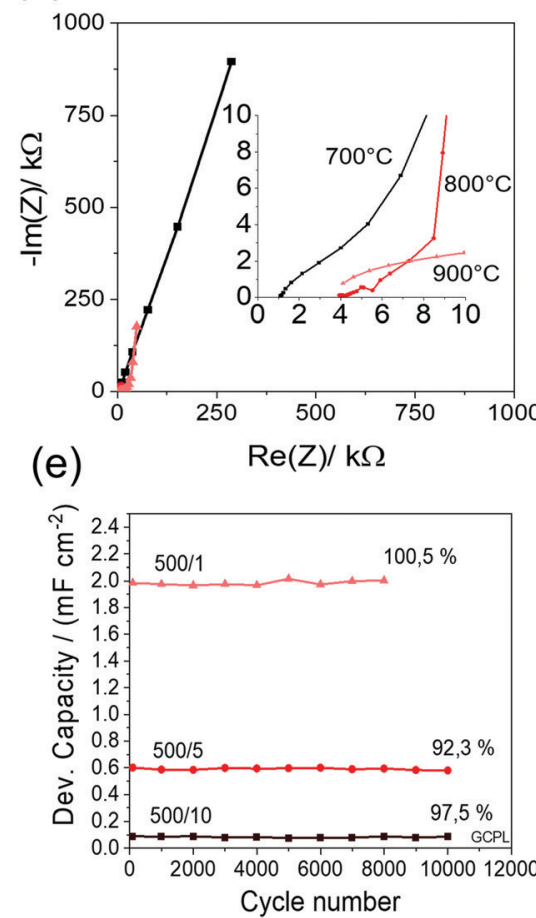

(c)

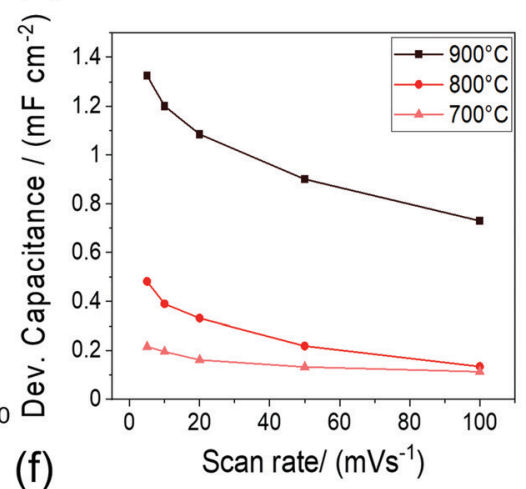

(f)

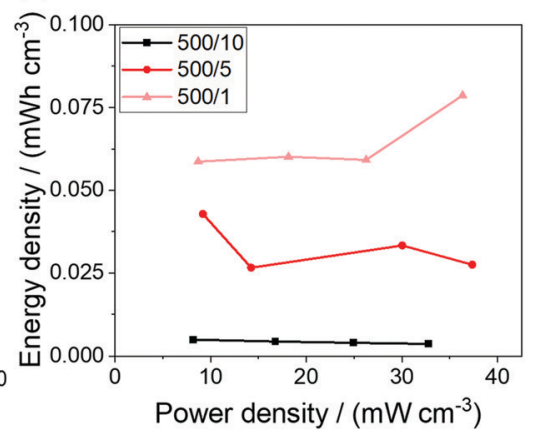

Fig. 6 Electrochemical characterization of the IDE 500/1 at different temperatures (CV-curves (a), Nyquist plot (b), rate capability (c); device capacitances of all structures at different temperatures (d), GCD cycling stability over 10000 cycles at $8.3 \mu \mathrm{A} \mathrm{cm}{ }^{-2}$ for all structures (e) and the Ragone plot (f) both for $900{ }^{\circ} \mathrm{C}$ pyrolysis temperature).

The mentioned trend can be seen for the IDE 500/5 structure as well (Fig. 6d).

However, beyond the discussed temperature influence, the fabrication of defect-free structures without cracks after carbonization is another crucial challenge to achieve high capacitances. This might cause the observed reverse trend for the IDE $500 / 10$, where the probability of line cracks is lower at reduced temperatures.

The electrode distance might play another important role when it comes to the fabrication of defect free MSCs. The interdigital structure with the smallest electrode distance (IDE 500/1) shows the highest number of electrode fingers and therefore the highest probability of line cracks and contact problems, which makes a fabrication of defect free MSCs with reproducible device capacitances more challenging. This influence, and the mentioned influence of lower conductivity, might cause the device capacitance drop from $900{ }^{\circ} \mathrm{C}$ to $800{ }^{\circ} \mathrm{C}$ for the IDE 500/1. However, high device capacitances for all structures could be reached.

To analyze the cycling stability of the fabricated MSCs, 10000 charge and discharge cycles are performed (Fig. 6e). For all structures, an excellent cycling stability could be observed, leading to a maximal capacity retention of $92 \%$. In the Ragone plot (Fig. 6f), all structures pyrolyzed at $900{ }^{\circ} \mathrm{C}$ showed similar power densities at different scan rates from 4.2 to $11.1 \mu \mathrm{A} \mathrm{cm}^{-2}$, because all structures exhibit the same line width of $500 \mathrm{~nm}$. However, the energy densities could be significantly improved with decreasing line distances and transport pathways, because of decreasing diffusion path length. Therefore, IDE 500/1 showed the highest energy density with an average of $0.07 \mathrm{~mW} \mathrm{~h} \mathrm{~cm}^{-3}$.

\section{Experimental}

\section{Precursor preparation}

The carbon precursor is synthesized using $0.340 \mathrm{~g}(2.981 \mathrm{mmol})$ of acetylene dicarboxylic acid $(97 \%$, abcr $\mathrm{GmbH})$ and $0.276 \mathrm{~g}$ (2.981 mmol) of glycerol (Carl Roth) solved in $0.16 \mathrm{ml}$ deionized water. To improve the polymerization, $32.4 \mathrm{mg}$ of sulfuric acid (95\%, Sigma Aldrich) is added.

\section{Compact film formation}

The thin films are prepared on pre-treated boro-aluminium silicate slides (Corning 1737, DELTA Technologies) $(25 \mathrm{~mm} \times 25 \mathrm{~mm} \times 1.1 \mathrm{~mm})$. In the pre-treatment step, the slides are stored in piranha solution (1 part $30 \% \mathrm{H}_{2} \mathrm{O}_{2}, 3$ parts conc. $\mathrm{H}_{2} \mathrm{SO}_{4}$ ) for at least 30 minutes, cleaned with deionized water and ethanol and dried in a nitrogen stream afterwards. Furthermore, the surface of the dried substrate is activated in argon plasma (kiNPen, Neoplas Tools). Thin films are formed by spin coating (Spin 150, ATP GmbH) $80 \mu$ l of the carbon precursor applied on the substrate using a speed of $2000 \mathrm{rpm}$ for 30 seconds. The thin films are dried at $100{ }^{\circ} \mathrm{C}$ and pyrolyzed 
in a tube furnace at temperatures between 300 and $900{ }^{\circ} \mathrm{C}$ with a heating rate of $150 \mathrm{~K} \mathrm{~min}^{-1}$ for $2 \mathrm{~h}$ under argon stream.

\section{Preparation of thin film supercapacitors}

To prepare layered EDLCs the pyrolyzed compact films are placed in acetone in order to separate them from the substrate and dried at $70{ }^{\circ} \mathrm{C}$. The two electrodes are coated with electroconductive varnish (electro-DAG) and afterwards with the dried films. To activate the electrodes, they are treated at $80{ }^{\circ} \mathrm{C}$ in vacuum overnight before additionally activation with $\mathrm{Ar}$ plasma. Afterwards, the hydrogel electrolyte is added (see electrolyte synthesis) and a polypropylene separator placed between the electrolyte layers. After drying both electrodes at $45{ }^{\circ} \mathrm{C}$ they are built together in a Swagelok setup.

\section{Nanoimprint lithography}

For the synthesis of interdigital patterned structures the solvent assisted nanoimprint lithography is applied using a microcontact-printing System $\mu$-CP $3.0 \quad$ (GeSim $\mathrm{mbH})$. The substrate-material and its pre-treatment is analogous to the compact films. The preparation of the patterned PDMS stamps (Sylgard 184 elastomer kit, Dow Chemicals) is described elsewhere. ${ }^{41}$ A droplet of $4 \mu \mathrm{l}$ precursor is applied onto the substrate before the stamp is pressed into it in order to fill the space in the stamp pattern. To receive an adequate solvent removal, the printing is carried out under constant pressure of $165 \mathrm{kPa}$ and temperature of $120{ }^{\circ} \mathrm{C}$ for 900 seconds. For an improved polymerization and curing of the precursor, the structure is irradiated with UV-light during the whole printing process. After peeling of the stamp, the structure is dried at $100{ }^{\circ} \mathrm{C}$ and pyrolyzed at the same conditions as the carbon films. In this work, three different interdigital structures are prepared with line widths of $10 \mu \mathrm{m}$ (IDE-1), $5 \mu \mathrm{m}$ (IDE-2) and $1 \mu \mathrm{m}$ (IDE-3) and maximum line heights and widths of $500 \mathrm{~nm}$ each. The structures are analyzed by atomic force microscopy (Dimensions D 3100, Digital Instruments) and SEM (DSM-982 Gemini, Zeiss) measurements.

\section{Electrolyte synthesis}

The used proton conductive electrolyte is a polymer hydrogel consisting of a mixture of polyvinyl alcohol (PVA; Merck; molecular weight 145000 ) and sulfuric acid in a ratio of $1: 1.2$. For an optimal amount $1 \mathrm{~g}$ of PVA $(0.0069 \mathrm{~mol})$ is added to $14 \mathrm{ml}$ deionized water and heated at $90{ }^{\circ} \mathrm{C}$ under constant stirring and reflux. Afterwards $1.2 \mathrm{~g}(0.0122 \mathrm{~mol})$ conc. sulfuric acid is added drop-wise so that a clear gel-like solution is created.

\section{Preparation of interdigital micro-supercapacitors and electrochemical characterization}

Possibly attached carbon residues are carefully removed before the interdigital structure is covered with silicone to protect it from the following deposition of a chrome $(10 \mathrm{~nm})$ and gold $(100 \mathrm{~nm})$ current collector. The physical vapor deposition (B39, Malz \& Schmidt) is performed with a deposition rate around $15-20 \mathrm{k}^{-1} \mathrm{~s}^{-1}$. Subsequently the silicon cover is removed, a
PMMA ring is applied around the structure area to create an isolation to the metal and confine the electrolyte in a defined area. After drying, the electrode surface is activated in argon plasma to increase the hydrophilicity and remove attached particles. After that, $10 \mu \mathrm{l}$ of the electrolyte is applied into the corresponding space.

For electrochemical characterization (VMP3 Potentiostat, Bio-Logic) cyclic voltammetry (CV) and electrical impedance spectroscopy (EIS) are performed. The CVs are recorded with a scanning rate between 5 to $100 \mathrm{mV} \mathrm{s}^{-1}$ in a voltage window of 0-0.8 V, while for the EIS analysis a frequency range from $5 \mathrm{mHz}$ to $100 \mathrm{kHz}$ is used.

\section{Conclusions}

In summary, an energy-rich carbon precursor system was successfully established as an ink in the SA-NIL process leading to highly defined interdigital structures with a line width down to $1 \mu \mathrm{m}$. By using pyrolysis temperatures between 700 and $900{ }^{\circ} \mathrm{C}$, stable, highly graphitic carbon electrodes for solid-state micro-supercapacitors could be obtained. Although the material showed no porosity, very high device capacitances up to $1.32 \mathrm{mF} \mathrm{cm^{-2 }}$ with an excellent cycling stability over 10000 cycles could be reached. Comparable microsupercapacitors with line widths of $500 \mathrm{~nm}$ and $1 \mu \mathrm{m}$ prepared via SA-NIL technique achieved areal capacitances of only $7.6 \mu \mathrm{F} \mathrm{cm}^{-2}$ and $23.1 \mu \mathrm{F} \mathrm{cm}^{-2}$ using sucrose derived carbon as precursor and $\mathrm{a}^{2} \mathrm{Li}_{2} \mathrm{SO}_{4}$-solution as electrolyte. ${ }^{22}$ Other comparable interdigital micro-supercapacitors based on 8 layers of CVD graphene using a PVA $/ \mathrm{H}_{2} \mathrm{SO}_{4}$ hydrogel as electrolyte and line distances of $70 \mu \mathrm{m}$ exhibit a device capacitance of $62.7 \mu \mathrm{F} \mathrm{cm}^{-2}$ but are difficult to print continuously. ${ }^{42}$

To further enhance the device capacitance, the specific surface area of the carbon material may be further enhanced. To increase the porosity, $\mathrm{CO}_{2}$-activation or the use of a template strategy are two possible options here for future development. However, an optimum between decreasing conductivity with increasing porosity should be considered. To improve the performance of the micro-supercapacitor at low carbonization temperature the reactivity of the precursor needs to be enhanced. In particular the content of polymerization agents i.e. glycerol should be minimized to achieve an enhanced reactivity of the acid. The development of new reactive precursor agents is a promising field for the SA-NIL technique to achieve defined carbonization at low temperatures for energy storage applications.

\section{Conflicts of interest}

There are no conflicts to declare.

\section{Notes and references}

1 S. A. Han, J. H. Lee, W. Seung, J. Lee, S. W. Kim and J. H. Kim, Small, 2019, 1903519, 1-14. 
2 H. Park, Y. Lee, N. Kim, D. Seo, G. Go and T. Lee, Adv. Mater., 2020, 32, 1903558.

3 Z. L. Wang, Adv. Mater., 2012, 24, 280-285.

4 S. Gong and W. Cheng, Adv. Energy Mater., 2017, 7, 1-33.

5 H. R. Lim, H. S. Kim, R. Qazi, Y. T. Kwon, J. W. Jeong and W. H. Yeo, Adv. Mater., 2020, 32, 1-43.

6 C. Lethien, J. Le Bideau and T. Brousse, Energy Environ. Sci., 2019, 12, 96-115.

7 P. Simon and Y. Gogotsi, Nat. Mater., 2008, 7, 845-854.

8 J. Cai, C. Lv, C. Hu, J. Luo, S. Liu, J. Song, Y. Shi, C. Chen, Z. Zhang, S. Ogawa, E. Aoyagi and A. Watanabe, Energy Storage Mater., 2020, 25, 404-415.

9 P. He, Z. Ding, X. Zhao, J. Liu, Q. Huang, J. Peng and L.-Z. Fan, Carbon N. Y., 2019, 155, 453-461.

10 Z. Pei, H. Hu, G. Liang and C. Ye, Nano-Micro Lett., 2017, 9, 19.

11 R. Kumar, E. Joanni, R. K. Singh, E. T. S. G. da Silva, R. Savu, L. T. Kubota and S. A. Moshkalev, J. Colloid Interface Sci., 2017, 507, 271-278.

12 M. F. El-Kady and R. B. Kaner, Nat. Commun., 2013, 4, 1475.

13 S. Sollami Delekta, A. D. Smith, J. Li and M. Östling, Nanoscale, 2017, 9, 6998-7005.

14 C. (John) Zhang, L. McKeon, M. P. Kremer, S. H. Park, O. Ronan, A. Seral-Ascaso, S. Barwich, C. Coileáin, N. McEvoy, H. C. Nerl, B. Anasori, J. N. Coleman, Y. Gogotsi and V. Nicolosi, Nat. Commun., 2019, 10, 1-9.

15 H. Li, X. Li, J. Liang and Y. Chen, Adv. Energy Mater., 2019, 9, $1-13$.

16 S. Liu, J. Xie, H. Li, Y. Wang, H. Y. Yang, T. Zhu, S. Zhang, G. Cao and X. Zhao, J. Mater. Chem. A, 2014, 2, 18125-18131.

17 C. (John) Zhang, M. P. Kremer, A. Seral-Ascaso, S. Park, N. McEvoy, B. Anasori, Y. Gogotsi and V. Nicolosi, Adv. Funct. Mater., 2018, 1705506, 1-10.

18 E. B. Secor, P. L. Prabhumirashi, K. Puntambekar, M. L. Geier and M. C. Hersam, J. Phys. Chem. Lett., 2013, 4, 1347-1351.

19 J. Li, S. Sollami Delekta, P. Zhang, S. Yang, M. R. Lohe, X. Zhuang, X. Feng and M. Östling, ACS Nano, 2017, 11, 8249-8256.

20 W. Yu, B. Q. Li, S. Ding and H. Liu, J. Micromech. Microeng., 2018, 28, 105014.

21 S. Abdolhosseinzadeh, J. Heier and C. Zhang, ChemElectroChem, 2021, 8, 1911-1917.

22 S. Lochmann, J. Grothe, K. Eckhardt, D. Leistenschneider, L. Borchardt and S. Kaskel, Nanoscale, 2018, 10, 10109-10115.
23 W. J. Hyun, E. B. Secor, C.-H. Kim, M. C. Hersam, L. F. Francis and C. D. Frisbie, Adv. Energy Mater., 2017, 7, 1700285.

24 Y. Xia and G. M. Whitesides, Annu. Rev. Mater. Sci., 1998, 28, 153-184.

25 W. Zhou, Nanoimprint Lithography: An Enabling Process for Nanofabrication, Springer Berlin Heidelberg, Berlin, Heidelberg, 2013.

26 S. Lochmann, Y. Bräuniger, V. Gottsmann, L. Galle, J. Grothe and S. Kaskel, Adv. Funct. Mater., 2020, 30, 1910439.

27 W. Li, Y. Li, M. Su, B. An, J. Liu, D. Su, L. Li, F. Li and Y. Song, J. Mater. Chem. A, 2017, 5, 16281-16288.

28 M. Qiu, P. Sun, G. Cui, Y. Tong and W. Mai, ACS Nano, 2019, 13, 8246-8255.

29 Y.-J. Kim, S. J. Kim, M. H. Jung, K. Y. Choi, S. Bae, S.-K. Lee, Y. Lee, D. Shin, B. Lee, H. Shin, M. Choi, K. Park, J.-H. Ahn and B. H. Hong, Nanotechnology, 2012, 23, 344016.

30 P. Zhang, F. Wang, M. Yu, X. Zhuang and X. Feng, Chem. Soc. Rev., 2018, 47, 7426-7451.

31 S. Xi, Y. Kang, S. Qu and S. Han, Mater. Lett., 2016, 175, 126-130.

32 L. Liu, D. Ye, Y. Yu, L. Liu and Y. Wu, Carbon N. Y., 2017, 111, 121-127.

33 L. Borchardt, M. Oschatz and S. Kaskel, Mater. Horiz., 2014, 1, 157-168.

34 G. Zhong, S. Hofmann, F. Yan, H. Telg, J. H. Warner, D. Eder, C. Thomsen, W. I. Milne and J. Robertson, J. Phys. Chem. C, 2009, 113, 17321-17325.

35 R. Atchudan, S. Perumal, T. N. Jebakumar Immanuel Edison and Y. R. Lee, RSC Adv., 2015, 5, 93364-93373.

36 P. Huang, M. Heon, D. Pech, M. Brunet, P.-L. Taberna, Y. Gogotsi, S. Lofland, J. D. Hettinger and P. Simon, J. Power Sources, 2013, 225, 240-244.

37 A. B. Bourlinos, M. A. Karakassides, P. Stathi, Y. Deligiannakis, R. Zboril, P. Dallas, T. A. Steriotis, A. K. Stubos and C. Trapalis, J. Mater. Sci., 2011, 46, 975-982.

38 M. Gasgnier, J. Mater. Sci. Lett., 2001, 20, 1259-1262.

39 S. H. Y. L. F. Chen, X. D. Zhang, H. W. Liang, M. Kong, Q. F. Guan, P. Chen and Z. Y. Wu, ACS Nano, 2012, 6, 7092-7102.

40 S. Lochmann, S. Kintzel, Y. Bräuniger, T. Otto, E. Zhang, J. Grothe and S. Kaskel, Chem. - Eur. J., 2021, 27, 1356-1363.

41 S. K. B. Schumm, P. Wollmann, J. Fritsch and J. Grothe, J. Phys. Chem. C, 2011, 21, 10697-10704.

42 J. Ye, H. Tan, S. Wu, K. Ni, F. Pan, J. Liu, Z. Tao, Y. Qu, H. Ji, P. Simon and Y. Zhu, Adv. Mater., 2018, 30, 1-8. 